\title{
ANDAR COM FÉ: O SIONISMO CRISTÃO E AS FRONTEIRAS POLÍTICO- IDENTITÁRIAS ENTRE O TURISMO RELIGIOSO E PEREGRINAÇÃO A ISRAEL
}

\section{WALK IN FAITH: CHRISTIAN ZIONISM AND THE POLITICAL-IDENTITY FRONTIERS BETWEEN RELIGIOUS TOURISM AND THE PILGRIMAGE TO ISRAEL}

Deborah Hornblas Travassos*

\begin{abstract}
Resumo: As viagens promovidas a Israel são cada vez mais procuradas por grupos evangélicos brasileiros que se declaram sionistas cristãos, e possuem o objetivo de encontrar uma terra milenar, local onde a profecia messiânica se dará com a volta de Jesus, segundo a doutrina dispensacionalista. Esses grupos religiosos têm encontrado amparo na ascensão da nova direita brasileira, que por sua vez, vem buscando um alinhamento político ao Estado de Israel; esse apoio possui como meta o voto evangélico cada vez mais abundante no Brasil. Um aspecto fundamental levantado são as diferenças entre peregrinação e turismo religioso, as fronteiras entre esses dois tipos de deslocamento são porosas e pouco delimitadas, e exatamente por conta dessas linhas borradas torna-se vantajoso declara-se peregrino, o que no caso estudado por esse artigo, possui a capacidade de legitimar os objetivos propostos por essas viagens.
\end{abstract}

Palavras-chave: Turismo religioso. Peregrinação. Sionismo cristão.

\begin{abstract}
The trips promove to Israel are increasingly sought after by Brazilian evangelical groups tato declare themselves Christian Zinistes, and have the objective of finding a millenary land, a place where the messianic prophecy will take place with the return of Jesus, according to the dispensationalist doctrine. These religious groups have found support in the rise of the new Brazilian right, which, in turn, has been seeking a political alignment with the State of Israel; this support has as its goal the increasingly abundant evangelical vote in Brazil. A fundamental aspect raised are the differences between pilgrimage and religious tourism, the borders between these two types of displacement are porous and poorly defined, and precisely because of these blurred lines it becomes advantageous to declare oneself a pilgrim, which in the case studied by this article, has the ability to legitimize the objectives proposed by these trips.
\end{abstract}

Keywords: Religious Tourism. Pilgrimage. Christian Zionism.

\footnotetext{
* Universidade de São Paulo (USP), São Paulo, Brasil, Doutora em Letras, pesquisadora do Centro de Estudos Judaicos (CEJ-USP). Email: <dtravassos@uol.com.br>.
} 


\section{Introdução}

Dentre as muitas possibilidades, a fim de analisar o turismo religioso e seus vários impactos e significados, surge a percepção de que essa forma de deslocamento reifica o sagrado tornando-o um produto dentro da lógica capitalista. Segundo Georg Lukács, a reificação é um processo histórico inerente às sociedades capitalistas, caracterizado por uma transformação experimentada pela atividade produtiva, pelas relações sociais e pela própria subjetividade humana, sujeitadas e identificadas cada vez mais ao caráter inanimado, quantitativo e automático dos objetos ou mercadorias circulantes no mercado. A reificação ou coisificação é uma operação mental que consiste em transformar conceitos abstratos em objetos, é o ato de transformar ideias em coisas concretas ${ }^{1}$.

Os lugares sagrados, com advento do capitalismo, deixaram de ser puramente locais de peregrinação e foram reificados transmutando-se à luz dos interesses econômicos. Esse artigo procurará refletir sobre essa hipótese, levando em conta como a pós-modernidade borrou essas fronteiras entre o sagrado e o profano.

Ainda podemos, dentro dessa perspectiva, destacar a teoria das trocas simbólicas de Bourdieu ${ }^{2}$. Para o autor, um campo se caracteriza pela definição dos objetos de disputa e dos interesses específicos, assim a estrutura do campo é uma condição da distribuição do capital específico. $\mathrm{O}$ autor analisa as origens e a estrutura do campo religioso, que ele define como um conjunto de práticas e representações, tratando-se de um sistema simbólico, que tem o poder de estruturar a sociedade. O simbólico indica que a subjetividade da experiência religiosa se materializa socialmente em práticas e discursos, quando encontra uma demanda social, dando sentido à existência dos indivíduos inseridos em determinados grupos ou classes.

O uso da teoria de Bourdieu sustenta a análise do sentido simbólico que constituem as viagens de peregrinação a Israel e o uso de símbolos judaicos pelas denominações evangélicas brasileiras, que assumem uma postura de que possuem mais direito à "Terra Santa", mais do que qualquer outro grupo, pois dizem ser herdeiros diretos dos primeiros que seguiram Jesus ainda em épocas neotestamentárias.

Falar de peregrinação, como um ritual religioso, nos leva a análise de Durkheim em "As formas elementares da vida religiosa". Nessa obra encontramos a dualidade entre o sagrado e o profano. Para o autor compreender a religião é identificar suas funcionalidades sociais: uma

\footnotetext{
${ }^{1}$ LUKÁCS, G. São Paulo: Martins Fontes, 1989, p.50.

${ }^{2}$ BOURDIEU, Pierre. Rio de Janeiro: Bertrand, 2012, p. 10.
} 
religião é um sistema solidário de crenças e de práticas relativas às entidades sagradas, são crenças e práticas que unem em uma mesma comunidade moral, chamada igreja ${ }^{3}$. Entre as práticas descritas pelo sociólogo, podemos inferir que é possível incluir nesta categoria a busca pelo sagrado através de jornadas sacrificiais, a que comumente chamamos de peregrinação.

O antropólogo inglês Victor Turner dedicou boa parte de sua obra ao estudo das simbologias usadas em rituais e definiu a noção de liminaridade; trata-se de uma situação transitória que se torna um momento fundamental, em que o sujeito apresenta uma morte social e renasce através de ritos de passagem, renascendo e reintegrando-se de outra forma a sociedade da qual ele faz parte. Segundo o autor, a vida social se organiza a partir de um movimento dialético, envolvendo estrutura social, estrutura e antiestrutura, alimentado pelas práticas rituais $^{4}$. A liminaridade, uma condição social transitória vivenciada por sujeitos temporariamente situados fora da estrutura social, dando origem ao que ele denomina communitas que é constituída pelos vínculos entre indivíduos ou grupos sociais que compartilham uma condição liminar em momentos especificamente ritualizados. A liminaridade de Turner pode ser vista dentro dos deslocamentos por motivos religiosos; a pessoa que empreende essa viagem, constituída por grupos de peregrinos/turistas religiosos, sente-se pertencente a algo maior e que transcende sua vida cotidiana e isso os estimula a buscar essas jornadas espirituais.

No sentido weberiano ${ }^{5}$, a peregrinação e turismo não se apresentam como etapas num processo histórico absolutamente retilíneo, mas são formas de interagir com o sagrado, porém suas fronteiras não são claras. O que vemos com cada vez mais força é deslocamento da ênfase do ponto de chegada para o peregrinar ou o viajar em si.

Esse artigo irá se ater ao peregrino/turista evangélico neopentecostal, essa escolha está fundada no apoio que parte desse grupo têm oferecido ao atual governo brasileiro e seu Presidente Jair Bolsonaro, e ao mesmo tempo por constituírem grande parte dos viajantes que procuram Israel como destino religioso.

Dentre outros importantes questionamento para esse artigo podemos elencar: qual a relação entre peregrinação/turismo religioso e a ascensão de ideologias de direita no Brasil? Se turismo e peregrinação não possuem fronteiras nítidas, como os evangélicos neopentecostais se autodefinem frente a essa dualidade? É observado no panorama político brasileiro atual, uma forte tendência ao alinhamento ao Estado de Israel, quais seriam as possíveis razões para o

\footnotetext{
${ }^{3}$ DURKHEIM, E. São Paulo: Martins Fontes, 1996, p.59.

${ }^{4}$ http://ea.fflch.usp.br/conceito/liminaridade-e-communitas-victor-turner, acesso em 10/02/2021.

${ }^{5}$ WEBER, Max. In WEBER, Max. Lisboa: Tribuna da História, 2005. p. 22 
governo atual, cuja liderança de Bolsonaro e seus ministros e seguidores próximos, defendam e profiram um discurso sionista calcado em princípios bíblicos/cristãos? São perguntas complexas que não pretendem ser esgotadas nesse texto.

\section{1- Peregrinação e turismo religioso: o espaço do sagrado}

Se o sagrado constitui um elemento fundamental na construção do espaço, existe de fato, como afirmou Durkheim em sua obra, uma separação nítida entre o sagrado e o profano? O espaço sagrado, que é o lugar da peregrinação, da busca salvacionista, da cura, da promessa etc. possui uma dimensão material, não se trata apenas de algo construído simbolicamente, ele existe fisicamente e é a sua materialidade que o torna atraente para os fiéis. Para Berger existe uma inter-relação entre a religião e o espaço: "há uma inter-relação entre religião, espaço e conhecimento, pois o ser humano: enfrenta o sagrado como uma realidade imensamente poderosa, distinta dele. Essa realidade a ele se dirige, e coloca a vida numa ordem, dotada de significado"6.

A palavra peregrino remete às jornadas realizadas por motivações religiosas e que envolvem sempre uma dose de sacrifício, que podem se configurar tanto nas dificuldades (as vezes extremas) encontradas nos trajetos percorridos até o local sagrado, como nas promessas feitas ao se alcançar o objeto de sua demanda, como por exemplo, caminhar de joelhos, ou carregar grandes cruzes. Já quando usamos o termo turismo religioso essas condições do sacrifício se diluem, pois nos levam a pensar em visitas com motivação religiosa que são facilitadas por toda uma estrutura moderna que produz conforto aos viajantes como hotéis, roteiros pré-estabelecidos, restaurantes, lazer e etc.

Os fiéis que usam a infraestrutura turística nos locais considerados sagrados podem sentir que a autenticidade de sua viagem foi perdida? Se sentem menos peregrinos? Ou essa é uma questão resolvida por outros caminhos? Como veremos os conceitos de turismo religioso e peregrinação se apresentam muito mais complexos e se interpenetram constantemente, não sendo possível considerá-los como estáticos e apartados um do outro.

Erik Cohen professor emérito do Departamento de Sociologia e Antropologia da Universidade Hebraica de Jerusalém, que estuda o turismo religioso, afirma em sua obra que há um continuum entre o peregrino e o turista, o peregrino busca o sagrado e acaba se transformando em turista que busca por autenticidade. Existe para o autor uma hibridização

\footnotetext{
${ }^{6}$ BERGER, P. São Paulo: Paulus, 2003. p. 46
} 
entre turista e peregrino, ou seja, um "peregrino-turista ou de um turista-peregrino". Essas são, portanto, categorias que expressam múltiplos significados, muitas vezes divergentes, que lhe conferem densidade e poder de mobilizar multidões. ${ }^{7}$

\section{1- Qual o significado de lazer e ócio?}

Se turismo pressupõe lazer e peregrinação sacrifício, podemos então afirmar que o peregrino evita a diversão? Começamos então com uma compreensão mais ampla do significado do lazer. Etimologicamente a palavra vem do latim e significa, segundo o dicionário Houaiss "aquilo que é permitido, lícito, o que pode ser feito" 8 .

O lazer não é um fenômeno isolado e se manifesta em diferentes contextos de acordo com os sentidos e os significados culturalmente produzidos/reproduzidos pelos sujeitos em suas relações com o mundo. O lazer participa da complexa trama histórico-social que caracteriza a vida na sociedade, e é um dos fios tecidos na rede humana de significados, dos símbolos e das significações. Na vida cotidiana o lazer constitui-se de relações dialógicas com outros campos além do trabalho, tais como a educação, a política, a economia, a linguagem, a saúde, a arte, a ciência e a natureza, entre outras dimensões da vida, sendo parte integrante e constitutiva de cada sociedade ${ }^{9}$. Esse termo é polissêmico e muito se alterou no decorrer da história, assim temos algumas definições:

O sociólogo francês Dumazedier, caracterizou lazer como:

[...] um conjunto de ocupações às quais o indivíduo pode entregar-se de livre vontade, seja para repousar, seja para divertir-se, recrear-se e entreter-se ou ainda, para desenvolver sua informação ou formação desinteressada, sua participação social voluntária ou sua livre capacidade criadora após livrar-se ou desembaraçar-se das obrigações profissionais, familiares. ${ }^{10}$

\footnotetext{
${ }^{7}$ COHEN, E. Greenwood Press, 1992, p. 29-46.

${ }^{8}$ https://houaiss.uol.com.br/corporativo/apps/uol_www/v5-4/html/index.php\#0, acesso em 05/02/2019.

${ }^{9}$ GOMES, Christianne.L.; ELIZALDE. Belo Horizontes, UFMG, 2012.p. 20.

${ }^{10}$ DUMAZEDIER, J. São Paulo: Perspectiva, 1976, p. 54.
} 
Já Marcuse ${ }^{11}$ declara que "[...]o lazer seria uma alienação, uma ilusão de autossatisfação das necessidades do indivíduo, porquanto estas necessidades são criadas, manipuladas pelas forças econômicas da produção e do consumo de massa, conforme o interesse de seus donos".

Derivado do latim o termo otium, significa o fruto das horas vagas, do descanso, e também possui o sentido de ocupação suave e prazerosa. Com advento do capitalismo, diferentemente do ócio contemplativo, as horas de lazer passaram a ser encaradas como algo pernicioso, diferente do trabalho que é visto como virtuoso. Para Herbert Marcuse, o sentido do ócio foi manipulado de tal maneira que se tornou um mecanismo gerador na direção da criação de falsas necessidades materiais.

A palavra lazer costuma vir associada ao entretenimento e ao turismo. Mas, se partirmos do pressuposto que o tempo de viagem é um período dedicado ao ócio, a ideia é perpassada por um valor negativo. Nas sociedades pré-industriais as atividades de lazer estavam, ao menos no Brasil, ligadas as celebrações religiosas e as tradições em geral, essas atividades eram vistas como produtoras de resultados morais e aceitas socialmente. O ócio é tão antigo quanto o trabalho, porém, somente após a ascensão do capitalismo, decorrente da Revolução Industrial inglesa do século XVIII, é que ocorre uma separação entre trabalho e lazer. O lazer encontrase submetido a um lugar de destaque, com funções de descanso e diversão. Por outro lado, o ócio, representa algo mais do que essas categorias, ele está no âmbito do hedonismo que é um comportamento condenado pelas sociedades judaico-cristãs, sendo estes fatores não condicionados inteiramente pelo social e sim pelo modo de viver de cada um, relacionado com o prazer da experiência ${ }^{12}$.

Se a ideia de turismo é entremeada com as palavras lazer e ócio, vemos uma tendência, por aqueles que buscam os lugares sagrados, sentirem-se peregrinos em suas jornadas, ao mesmo tempo que observa-se uma rejeição a ideia da diversão, e, portanto, do turismo. Daí a recorrência do uso quase que onipresente da palavra peregrinação em suas narrativas.

\section{2- Turismo Religioso e Peregrinação: duas faces da mesma moeda}

Para a igreja católica existem nas viagens as duas possibilidades de vivência religiosa: $\mathrm{O}$ turismo religioso e a peregrinação. O Vaticano, por exemplo, parte do princípio de que existem diferenças claras entre os objetivos e as sensações provocadas pelas intenções de

\footnotetext{
${ }^{11}$ MARCUSE, H. Madrid: Alianza Editorial, 1971, p. 50.

12 DUMAZEDIER, J. São Paulo: Perspectiva, 1976, p. 54 
deslocamentos. Para essa linha de pensamento a peregrinação pressupõe basicamente obrigação e sacrifício, enquanto o turismo religioso pode ser definido como uma visitação a lugares sacros, sem que haja obrigatoriamente algum tipo de envolvimento de fé, mesmo porque a pessoa que visita um lugar considerado santo não necessariamente professa a religião daquele sítio, é o caso, por exemplo, de judeus ou muçulmanos que visitam a Basílica de São Pedro, nesse caso lazer e prazer convivem no mesmo espaço do sagrado.

Na definição da Conferência Mundial de Roma, realizada no ano de 1960, o turismo religioso é compreendido como uma organização que movimenta inúmeros peregrinos em viagens pelos mistérios da fé ou da devoção a algum santo. João Paulo II em seu discurso feito em 17 de outubro de 1980 no Vaticano disse:

Gostaria, enfim, de vos ajudar a suportar as vossas preocupações pastorais. Conheço a vossa inquietude no sentido de enquadrar ou, pelo menos, educar um «turismo religioso» que se desenvolve paralelamente à expansão das verdadeiras peregrinações, com a única finalidade de visitar os sublimes lugares espirituais. Importa manter com os responsáveis e animadores de tal turismo, um relacionamento e um diálogo que possam dar os seus frutos com o tempo ${ }^{13}$.

O discurso acima mostra que há uma preocupação do Vaticano, em separar o turismo religioso da chamada verdadeira peregrinação. Para a Igreja de Roma a peregrinação realiza-se de diversas maneiras: as peregrinações aos locais sagrados que a fé professa, as festas religiosas, aos espetáculos e as representações teatrais de cunho religioso, congressos, encontros e seminários ligados à evangelização. Mas, dentro da perspectiva desse artigo, será que os evangélicos neopentecostais brasileiros compartilham dessas ideias? A separação entre essas duas categorias de deslocamento é tão clara para esses grupos como para os católicos? O que se verifica na prática, através do conteúdo de divulgação de agências de turismo e operadoras brasileiras que atendem ao público neopentecostal, essa separação entre turismo religioso e peregrinação não existe, mas isso também é notado em agências de viagens católicas:

A agência Caminhando com Maria, que atende ao público católico brasileiro usa somente o termo peregrinação para oferecer seus pacotes de viagem, não só para Israel, mas também para outras localidades importantes para os católicos como Roma, Lourdes na França, Fátima

\footnotetext{
${ }^{13}$ http://gsearch.vatican.va/search, acesso em 18/05/2011.
} 
em Portugal etc. ${ }^{14}$. Isso também ocorre com os pacotes oferecidos pelas agências que oferecem suas opções de deslocamentos aos evangélicos neopentecostais, como por exemplo, a Terra Santa Viagens, a maior empresa brasileira voltada para esse público, que também só usa o termo peregrino $^{15}$.

A cartilha "Turismo Cultural: Orientações Básicas" criada pelo Ministério do Turismo (MTur) em 2008 ressalta que os deslocamentos motivados por interesses religiosos, místicos, esotéricos, cívicos e étnicos são entendidos por esta entidade como recortes no âmbito do Turismo Cultural, "e podem constituir outros segmentos para fins específicos: Turismo Cívico, Turismo Religioso, Turismo Místico e Esotérico e Turismo Étnico". Ainda nessa cartilha "o Turismo Religioso configura-se pelas atividades turísticas decorrentes da busca espiritual e da prática religiosa em espaços e eventos relacionados às religiões institucionalizadas”. Para MTur religiões institucionalizadas são aquelas que apresentam doutrina, hierarquia, estruturas, rituais, sendo o grupo que engloba aquelas de origem oriental, afro-brasileiras, espíritas, protestantes e católicas ${ }^{16}$

De acordo com Dias ${ }^{17}$, a palavra peregrino tem sido mais associada à experiência individual vivida por quem realiza a jornada, sendo que o peregrino não se sente como um turista. Os locais religiosos transformam-se em momentos de aproximação entre pessoas que compartilham a mesma fé e religião. Esses locais podem ser classificados em termos de significância religiosa aos objetos de devoção (milagres, relíquias, imagens). Para Burns ${ }^{18}$, a dominação capitalista da cultura e, por conseguinte do Turismo pela mercantilização, perverte suas consequências sociais quando busca inserir os cidadãos no universo das regras de consumo.

Autor de várias obras sobre turismo, o brasileiro Mário Beni ${ }^{19}$ alia a visão da Antropologia com conceitos mercadológicos, ao afirmar que o turista é aquele que se desloca para outros lugares a partir de escolhas e motivações variadas; já o peregrino se concentra na motivação religiosa, contudo ele é um turista, pois na atualidade há uma tendência cada vez mais forte da mercantilização da fé. Assim, sem dúvida haverá consumo na viagem com fins religiosos, meios de hospedagem serão utilizados, alimentação, souvenires, etc. Os peregrinos

\footnotetext{
14 https://caminhandocommaria.com/roteiros/terra-santa-avivamento-09-dias-pe-fabio-de-melo, acesso em 02/02/2020.

15 www.terrasantaviagens.com.br, acesso em 10/11/2020.

${ }^{16}$ https://www.gov.br/turismo/pt-br. 2008, p.18.

${ }^{17}$ DIAS, R. in DIAS, R. e SILVEIRA, E.J.S. da (orgs.).Campinas, SP: Alínea, 2003 (p. 7-37).

${ }^{18}$ BURNS, P. São Paulo: Chronos, 2002. p.54

${ }^{19}$ BENI, M. C. São Paulo: SENAC, 2000. p. 21.
} 
assumem um comportamento de consumo turístico, pois utilizam equipamento e serviços com estrutura de gastos semelhantes aos turistas comuns.

O turismo religioso apresenta características que coincidem com o turismo cultural escolhido por determinados grupos. Para Dias ${ }^{20}$ o turismo baseado na fé, no entanto, não está restrito as peregrinações, esses deslocamentos podem ocorrer por outras motivações como: trabalhos missionários, interesses arqueológicos ou antropológicos por sítios considerados sacros, a busca de lazer nas festas de cunho religioso, entre tantos outros possíveis motivos que não estão ligados ao sentido de peregrinação que envolve sacrifício/obrigação. Essa comercialização de um mercado da fé é cada vez mais utilizada pelas operadoras de viagem e turismo especializadas em destinos religiosos e que apresentam seu produto como uma peregrinação.

Mircea Eliade ${ }^{21}$ considera a peregrinação um tipo de viagem que faz parte da necessidade humana de procurar por espaços sacros. Para o antropólogo o homem procura viver sempre o mais proximamente possível daquilo que ele considera sagrado. Assim, o profano e o sagrado constituem duas possíveis formas do homem se ver no mundo, mas mesmo quando há um desejo intenso de dessacralização, traços de religiosidade ainda podem ser detectados. Se há uma fronteira entre o religioso e o não religioso, como ela se manifesta em busca de espaços sacros? Se o homem necessita estar perto do sagrado, e isso nem sempre é possível, a única solução será locomover-se até o local de manifestação da sua fé, o que Eliade chamou de centro do mundo, que pode ser uma cidade inteira ou um templo ${ }^{22}$.

Em qual momento a peregrinação repleta de motivações de fé se transformou em um negócio? Como fora descrito anteriormente são várias as motivações que levam as pessoas a realizar deslocamentos em busca do que é considerado sagrado, pode ser a renovação da fé, a cura ou o agradecimento. Mas, também é verificado uma clara associação desses deslocamentos com a compra de serviços e produtos.

No mundo ocidental as peregrinações cristãs tradicionais e primitivas, já existiam nos primeiros séculos do cristianismo e segundo a tradição católica a primeira peregrina teria sido Santa Helena que foi esposa de Constâncio Cloro e mãe do imperador romano Constantino, teria sido ela quem descobriu o local de crucificação de Jesus Cristo, tendo sido lá erguida a Basílica do Santo Sepulcro no ano de 337 d.C.

\footnotetext{
${ }^{20}$ Ibidem.

${ }^{21}$ ELIADE, Mircea. São Paulo: Martins Fontes, 2001, p.27

${ }^{22}$ Ibidem.
} 
Os primeiros estabelecimentos ligados às peregrinações teriam institucionalizado a atividade com o surgimento de hospedarias e estalagens nos caminhos percorridos pelos viajantes. O turista religioso é um herdeiro direto dos primeiros peregrinos, ele atualiza o objetivo de seu deslocamento adaptando suas necessidades conforme o contexto socioeconômico a qual ele está inserido . Em termos analíticos, a peregrinação e o turismo se apresentam como duas categorias de valores e sentidos distintas. No entanto, no nível prático esses campos aparecem emaranhados tornado suas fronteiras pouco perceptíveis ${ }^{23}$.

Como foi citado anteriormente o capitalismo fruto da Revolução Industrial, irá trazer à tona rupturas entre o significado de lazer, produzindo uma dialética entre ócio-lazer/trabalho. Nessa época surge pela primeira vez o conceito de turismo religioso como uma oportunidade de unir o lazer e a religião. A partir do século XIX ocorre um florescimento do turismo religioso produzindo novos sentidos, Vilas Boas ${ }^{24}$ afirma que "Assiste-se a um renascer religioso, com a reconstituição de imensas ordens religiosas que impulsionaram novamente as peregrinações”.

A peregrinação, apesar de manter a sua função espiritual, está inexoravelmente imbricada ao turismo, isso porque dificilmente uma pessoa conseguiria se deslocar sem usar a estrutura do mercado turístico, seja o uso de um avião, de um meio de hospedagem, de um restaurante, ou até a compra de ingressos para a visitação do objeto de sua busca.

Podemos afirmar que a peregrinação é um costume que permeia a sociedade desde os tempos mais remotos. Ela surgiu no mesmo momento em que o homem partiu em busca de um sentido maior para a sua existência. "A peregrinação existe porque se crê que as coisas, lugares e pessoas possuem graus de sacralidade distintos. E o ser humano tem necessidade e atração pelas coisas mais sagradas" 25 . A jornada dos peregrinos tem o intuito de antes de qualquer coisa a conquista do mérito espiritual.

Para Abumansur, entretanto, as operadoras de turismo e agências de viagens, dentro da sua lógica capitalista, não distinguem a motivação do turista ao oferecer o seu produto. Já quando se trata de turismo religioso a abordagem está intrinsecamente associada ao lazer, eventos religiosos que demonstram uma interação do sagrado com o profano. Podemos classificar a ideia de profano como uma manifestação desvinculada da conotação religiosa e que está inequivocamente associada à sensação de lazer/prazer e conectado com os princípios dos negócios ligados ao turismo.

23 file://C:/Users/dtrav/Downloads/113341-Texto\%20do\%20artigo-223839-1-10-20160908.pdf , acesso em $02 / 02 / 2021$.

24 VILAS BOAS, Nuno Fernando de Sá. Braga: 2012, p.29.

${ }^{25}$ ABUMANSUR, E.S, in ABUMANSUR, E. S. (org). Campinas, SP: Papirus, 2003, p. 53-56. 
Segundo a OMT (Organização Mundial do Turismo), não está claro o impacto sociocultural provocado pelo turismo religioso e como ele se diferencia da peregrinação. Dentro da lógica da OMT, o turismo religioso movimenta em todo o mundo mais de 330 milhões de pessoas por ano, que procuram lugares sagrados. Ainda segunda essa organização (dados de 2020), $56 \%$ dos turistas viajam a lazer, $27 \%$ por motivos religiosos, $12 \%$ a negócios e $5 \%$ são motivos não especificados. Esse movimento, que vem aumentando cada vez mais, é definido como Turismo da Fé, que contempla os mais diversos destinos e que atendem todos os tipos de crença, como o islamismo, judaísmo e o cristianismo. Os números são crescentes quando se trata de pessoas que viajam para participar de eventos religiosos, tais como nascimentos, casamentos, rituais de passagem e funerais ${ }^{26}$.

Se em períodos mais remotos, a organização das viagens eram atividades complexas e exigiam muito tempo de planejamento, isso não ocorre mais. Porém, superadas as grandes dificuldades de deslocamentos, o que se verifica atualmente é a necessidade de ajustar o calendário religioso às férias, que muitas vezes não podem ser usufruídas em datas religiosas. Isso nos remete a uma necessidade absolutamente secular. Essa adaptação tem levado a um novo ponto de contato entre turismo religioso e peregrinação que os torna indissociáveis. Podemos então dizer que a peregrinação foi secularizada.

Dentro da perspectiva do turismo como uma atividade econômica usando como ponto de partida a lógica capitalista, o turismo em todas as suas manifestações envolve a cadeia produtiva de todo o setor. O conceito de cadeia produtiva foi ampliado visando não apenas a relação comercial das empresas do setor, mas também a relação de poder e dependência entre eles e é atualmente estudado como rede de negócios ${ }^{27}$.

Um recente estudo apresentado pela OMT mostrou Israel na preferência dos turistas baseados na fé monoteísta. Nessa perspectiva é muito importante que o local visitado seja um centro religioso reconhecido como pilar de fé, como é o caso da cidade de Jerusalém. A maioria dos locais que são escolhidos como destino religioso não têm a importância de Israel, isso não significa, no entanto, que um local não possa desenvolver essa potencialidade.

Ao contrário do pensamento corrente durante o século XIX, que afirmava que a religião fatalmente iria se encolher à esfera privada e a ciência seria o novo Deus, e assim perderia protagonismo nas sociedades, o que é observado no mundo atualmente é um aumento das religiosidades, embora estas se comportem de maneira bastante fluida, como por exemplo, no

\footnotetext{
${ }^{26} \mathrm{https}$ ://www.unwto.org/global-and-regional-tourism-performance, acesso em 02/02/2021.

${ }^{27}$ PEREIRA, M. Alemanha: Novas edições acadêmicas, 2017. p.25
} 
caso do Brasil em que a pertença religiosa vem se alterando significativamente, todavia é necessário dizer que o cristianismo permanece como a fé quase monopolista, entretanto migrando para outras denominações não católicas nas últimas décadas, enquanto que outras religiões tradicionais como as de matriz africana vem encolhendo, como segue abaixo:

Quadro 1: Censo IBGE 2010. Percentual das principais religiões professadas por brasileiros em 2010:

\begin{tabular}{|lr|}
\hline Católica & $64,6 \%$ \\
\hline Evangélica & $22,2 \%$ \\
\hline Espíritas & $2,0 \%$ \\
\hline Sem religião & $8,0 \%$ \\
\hline
\end{tabular}

Quadro elaborado pelo autor com base nas estatísticas elaboradas pelo IBGE $^{28}$.

O último censo no Brasil foi feito há mais de dez anos e está muito desatualizado, o recenseamento da população não foi realizado como é previsto pela legislação, por conta da crise sanitária provocada pela pandemia de Covid-19. Em função dessa dificuldade foi consultado o instituto de pesquisa DataFolha que é um departamento do jornal Folha de S. Paulo, que como é sabido não é um órgão oficial, essa pesquisa foi realizada em 2020 e fez uma projeção das pertenças religiosas na atualidade, e nos dá uma medida das mudanças:

Quadro 2: DataFolha 2020. Percentual das principais religiões professadas por brasileiros em 2020:

\begin{tabular}{|lr|}
\hline Católica & $50,0 \%$ \\
\hline Evangélica & $31,0 \%$ \\
\hline Espíritas & $3,0 \%$ \\
\hline Sem religião & $10,0 \%$ \\
\hline
\end{tabular}

Quadro elaborado pelo autor com base nas estatísticas elaboradas pelo Instituto DataFolha. ${ }^{29}$

Pelos quadros verificamos que houve uma expressiva queda no número de católicos ($23 \%$ ) e inversamente um aumento do número de evangélicos (aumento de $+39,3 \%$ ) em um espaço de dez anos. Apesar de um aumento de $2 \%$ entre 2010 e 2020 de pessoas que se declaram

\footnotetext{
${ }^{28}$ https://www.ibge.gov.br/, acesso em 10/02/2021.

29 https://g1.globo.com/politica/noticia/2020/01/13/50percent-dos-brasileiros-sao-catolicos-31percentevangelicos-e-10percent-nao-tem-religiao-diz-datafolha.ghtml, acesso em 10/02/2021. 
"sem religião", o aumento do número de viagens internacionais de brasileiros com objetivos de peregrinação/turismo religioso aumentou significativamente:

Segundo a Embratur (Instituto Brasileiro de Turismo) ${ }^{30}$ em 1999 cerca de 15 milhões de brasileiros procuravam um destino religioso, já em 2002 houve um aumento de 7\% nesse número. Em 2018 se registrou um crescimento de mais de $60 \%$ em relação a 2010 no número de evangélicos adeptos ao turismo religioso, uma prática que até então era popular entre os católicos.

Nota-se assim que há uma permanência da religião do seu papel-chave na construção dos valores, não só individuais, mas também do grupo, pois ela dá a condição de urdir a essência de determinados comportamentos, a partir de valores básicos e compartilhando uma moralidade religiosa ${ }^{31}$.

\section{3- O sionismo cristão e a nova direita brasileira: Dispensacionalismo}

As religiões de matriz judaico-cristã sempre viram em Israel um local sagrado, sendo muito comum identificarem o país não como um país moderno, fundado em 1948, mas como um lugar espiritual, a Terra Prometida por Deus, de onde o Messias veio e para onde um dia voltará. Dessa forma deve-se identificar a qual Israel os grupos de evangélicos neopentecostais procuram e se há uma busca apenas à Terra de Israel (milenar) ou o Estado de Israel (secular), ou se existe uma procura por um misto das duas possibilidades.

A doutrina do dispensacionalismo pode contribuir no sentido de fornecer indicadores sobre o significado de Israel para várias denominações evangélicas. Segundo essa doutrina, a segunda vinda do Messias, será um acontecimento que se dará em Jerusalém ${ }^{32}$. A palavra dispensação deriva de um termo latino que significa administração ou gerência e refere-se ao método divino de lidar com a humanidade através de alianças e de administrar suas promessas. Para os defensores da doutrina dispensacionalista, a história humana está compreendida em um plano traçado e que este pode ser identificado através das interpretações da Bíblia Sagrada. Essas dispensações são identificadas em períodos bíblicos distintos.

A dispensação é uma interpretação teológica que estabelece uma forma específica de observar a Bíblia e suas narrativas, seria uma espécie de métrica para determinar o nível de relacionamento com Deus. Os dispensacionalistas dão profunda importância a distinção entre

\footnotetext{
${ }^{30}$ https://embratur.com.br/, acesso 1204/2019.

${ }^{31}$ CARLETTI, CARLETTI, Anna e FERREIRA, Marcos A. Curitiba: Juruá, 2016. p..58

${ }^{32}$ TOPEL, Marta. ANPUH, ANO IV, n.10, maio de 2011.
} 
Israel, Igreja e as Nações da Terra, o Israel histórico e político, descaracterizaria o movimento. Para essa doutrina, a nação judaica tem um papel de extrema importância e bem peculiar nas administrações divinas para a humanidade. A proposta dispensacionalista se opõe à doutrina da Teologia da Substituição ${ }^{33}$, pensamento que inviabilizaria as apropriações simbólicas ${ }^{34}$.

O surgimento da valorização de Israel e das raízes judaicas começa a predominar no cenário evangélico neopentecostal brasileiro, que por vezes são acusados por outras denominações pentecostais de judaizantes. A chamada judaização faz referência à presença de ritos e símbolos judaicos nas igrejas neopentecostais. Os símbolos judaicos são inseridos nos ritos como um capital simbólico funcional, trata-se, pois, de uma resposta à necessidade de manutenção do sagrado. Assim o dispensacionalismo é visto ou identificado como fenômeno judaizante por apresentar uma aceitação de um Israel não somente milenar, mas também secular, um país moderno fundado em 1948.

Nas eleições para a Presidência República em 2018, a sociedade brasileira dividiu-se em dois grupos ideológicos distintos, um que apoiou o então candidato Jair Bolsonaro e outro que reuniu os votos mais progressistas. Bolsonaro usou durante e após sua campanha um discurso pró-Israel, o que o fez obter os votos, não só de grande parte dos membros das igrejas evangélicas, importante celeiro de eleitores, mas também de boa parte da comunidade judaica brasileira, que é bem pequena, girando em torno de 120 mil pessoas, deixando explícito que o voto dos judeus é praticamente insignificante perto de uma população de 210 milhões de habitantes.

Jair Bolsonaro, que é considerado de extrema-direita, é de origem católica, mas foi batizado na igreja Assembleia de Deus, a cerimônia de batismo ocorreu no Rio Jordão e foi realizada pelo pastor Everaldo em 2016. A Primeira-Dama Michelle Bolsonaro faz parte da igreja Batista Atitude. O casal teve a sua cerimônia de casamento realizada pelo pastor Silas Malafaia, da Igreja Assembleia de Deus Vitória em Cristo, uma denominação neopentecostal. $\mathrm{Na}$ agenda da atual política brasileira os discursos teológicos das igrejas evangélicas inauguraram um entrelaçamento entre religião e política.

Dentre os processos legitimadores entre os evangélicos neopentecostais está o uso de símbolos laicos judaicos e nota-se que atualmente verificamos o uso desses símbolos em manifestações políticas no Brasil. Os brasileiros têm se acostumado a ver nas manifestações

\footnotetext{
${ }^{33}$ Teologia da substituição é uma interpretação cristã do Novo Testamento que vê a relação de Deus com os cristãos como sendo ou de substituição da promessa feita aos judeus. É a ideia de que uma Nova Aliança com os cristãos e a Igreja cristã teria substituído a Torá (Pentateuco).

${ }^{34}$ https://ri.ufs.br/bitstream/riufs/7153/2/CANDIDO_LUIZ_SANTOS_MAYNARD.pdf, acesso em 08/12/2020. 
políticas de direita o uso da bandeira de Israel. Talvez a falta de estranhamento da utilização de um símbolo nacional de outro país, esteja no fato que historicamente as esquerdas costumam empunhar em suas manifestações políticas bandeiras palestinas; e esse é um contraponto que marca fortemente as fronteiras entre os dois grupos de ideologias distintas. $\mathrm{O}$ atual governo ultraconservador e que representa a ascensão de uma nova direita, reproduz um pensamento maniqueísta simples de "nós contra os outros" para se manter no poder. Se a esquerda em algum momento se manifestou a favor da chamada causa palestina, torna-se um caminho óbvio, para a direita ultraconservadora, ver Israel como um aliado. Segundo Michel German o discurso político da nova direita brasileira "estabeleceu uma ruptura do sionismo hegemônico, laico e democrático, com posturas sionistas ultraconservadoras" . Ainda segundo o historiador: "Produz-se, assim, um Israel imaginário e, ao mesmo tempo, um judeu imaginário, que tem muito pouco a ver com Israel e com os judeus reais". 35

A nova direita brasileira é assim denominada, pois constitui um discurso ideológico que vai além da defesa da propriedade privada e do liberalismo econômico, ela produz pensamentos extremamente conservadores em termos de comportamento social, negando, por exemplo, que haja racismo e homofobia no Brasil. Além dessa abordagem da condução de uma política interna, verifica-se nesse novo governo um alinhamento político e ideológico com os EUA e seu presidente Trump (até janeiro de 2021), que mudou a embaixada norte-americana para Jerusalém. O Brasil indicou que pretende fazer essa mudança de endereço da embaixada, apesar dos riscos de retaliação econômica por parte dos países árabes, importantes parceiros comerciais em diversas áreas, assim como haverá fortes mudanças na forma como o Brasil será visto internacionalmente. ${ }^{36}$

Esse diálogo entre Brasil e Israel se baseia em argumentos bíblicos para defender que Jerusalém deve ser protegida e ficar inteiramente nas mãos dos judeus. Bolsonaro inclusive sinalizou que fechará a Embaixada da Autoridade Palestina em Brasília. Sua justificativa para essa atitude é que para ele a Palestina não é um país e, portanto, não tem o direito de manter embaixada em território brasileiro. Após meses de incertezas, o Governo do Brasil decidiu pela abertura de um escritório comercial em Jerusalém, adiando a decisão final. Apesar do recuo, ao menos por enquanto, o Ministério das Relações Exteriores do Brasil anunciou em 2019, que a pauta da mudança permanece no seu governo.

\footnotetext{
35 https://link.springer.com/article/10.1007/s41603-019-00078-y, acesso em 16/02/2021.

36 https://epoca.globo.com/mundo/israel-imaginario-usado-politicamente-pela-direita-pela-esquerda-23822015, acesso em 19/12/2020.
} 
Tanto no Brasil como nos EUA a aproximação com os evangélicos foi de fundamental importância nas eleições presidenciais de Bolsonaro e de Trump. Segundo o centro de pesquisa norte-americano Pew Research Center, os evangélicos perfazem um quinto do eleitorado norteamericano e um terço dos que simpatizam com o Partido Republicano, de Donald Trump. Na eleição de 2016, ele recebeu $81 \%$ dos votos desse segmento. Na cerimônia de abertura da embaixada dos Estados Unidos em Jerusalém, em 14 de maio de 2018, aniversário de 70 anos da criação do Estado de Israel, contou com sermões de dois importantes pastores evangélicos norte-americanos: Robert Jeffress, da Primeira Igreja Batista de Dallas e de John Hagee, do Ministério Cristãos Unidos por Israel ${ }^{37}$.

No caso do Brasil, no segundo turno da eleição, as intenções de voto segundo a pertença religiosa foram segundo pesquisa do Instituto DataFolha em $2018^{38}$ :

Bolsonaro: $51 \%$ dos católicos, $69 \%$ dos evangélicos, 30\% das religiões de matriz afrobrasileiras, $36 \%$ de ateus/agnósticos.

Fernando Haddad: 49\% dos católicos, 31\% dos evangélicos, $70 \%$ das religiões de matriz afro-brasileiras e $64 \%$ de ateus/agnósticos.

Nota-se, que embora Bolsonaro tenha tido uma leve vantagem entre os votos dos católicos (que são $50 \%$ da população brasileira), o que foi decisivo para que ele vencesse as eleições foram os votos dos evangélicos (foram $31 \%$ dos votos, e são o segundo lugar no Brasil em termos de pertença religiosa). Além do aspecto religioso, havia e há um forte pragmatismo nas relações internacionais, pois o Brasil viu vantagens econômicas na aproximação cada vez maior com os EUA, além de um alinhamento ideológico com os líderes de direita como Trump e Netanyahu.

As viagens bíblicas ou as peregrinações a Israel realizadas por protestantes norteamericanos das mais diversas denominações, tornaram-se muito comuns a partir da década de 1970, em que ficou nítida a política de aproximação dos Estados Unidos com Israel. Esses cristãos protestantes tiveram importante papel nesse alinhamento político utilizando doutrina dispensacionalista para justificar seu amor pela "Terra Santa" exigindo um maior engajamento do governo em prol de Israel.

Muitas organizações para-eclesiásticas foram fundadas a partir da década de $1980 \mathrm{em}$ território norte-americano com o propósito de apoiar o Estado de Israel, como por exemplo: a Jews for Jesus, 1973 (Judeus para Jesus) foi criada por um pastor batista com foco na

\footnotetext{
${ }^{37}$ https://www.bbc.com/portuguese/brasil-47776408, acesso em 19/12/2019.

38 https://g1.globo.com/politica/eleicoes/2018/noticia/2018/10/18/datafolha-para-presidente-votos-validosbolsonaro-59-haddad-41.ghtml, aceso em 19/12/2019.
} 
evangelização de judeus; Bridges for Peace, 1976 (Pontes para a Paz), encorajou judeus da União Soviética a emigrarem para Israel; National Christian Leadership Conference for Israel, 1978 (Conferência Nacional de Liderança Cristã para Israel) foi criada para influenciar a opinião pública norte-americana; Christians for Israel, 1979 (Cristãos por Israel) pauta suas atividades em ações humanitárias para judeus, publica artigos pró Israel e anti-Palestina; Christian Friends of Israel, 1985 (Amigos Cristãos de Israel); Unity Coalition for Israel , 1991 (Coalisão Unida por Israel), missão judaico-cristã de apoio a Israel, contou com palestras do Primeiro Ministro Benjamin Netanyahu; Christians United for Israel, 2006 (Cristãos Unidos por Israel), auto intitulada maior organização cristã pró-Israel nos EUA ${ }^{39} 40$.

No Brasil, o sionismo cristão na cultura evangélica brasileira, está profundamente escorado no dispensacionalismo norte-americano e nos movimentos das políticas estadunidenses pró-Israel. Essa influência é verificada na televisão e internet, que nos últimos anos tem sido uma ferramenta de comunicação frequentemente utilizada pelas mais variadas denominações evangélicas. A IURD (Igreja Universal do Reino de Deus), por exemplo, possui um dos mais importantes canais abertos de televisão, a Rede Record, que transmite farta programação de conteúdo religioso. É comum a presença, nos cultos televisionados, a bandeira do Estado de Israel e outros símbolos judaicos religiosos como a menorá (candelabro de sete braços) e é muito comum vermos os pastores realizando o culto usando kipá (solidéu) e talit (xale de orações), objetos que até então só eram portados por judeus.

Segundo o sociólogo e pastor da Assembleia de Deus, Gedeon Freire de Alencar, o sionismo cristão não foi percebido no cenário político do Brasil até recentemente, a explicação para esse fenômeno pode ser encontrada na esperança milenarista dos evangélicos brasileiros. O reconhecimento das raízes bíblicas do povo judeu contemporâneo tem como consequência não só um alinhamento religioso, mas político também. Ainda segundo o sociólogo as peregrinações a Israel se tornaram um desejo constante entre os evangélicos no que ele chama de "um sionismo ingênuo". ${ }^{41}$

Por outro lado, a bancada evangélica no Congresso Nacional brasileiro está cada vez mais numerosa e, com isso, busca mais poder e cargos relevantes. Em 1994, eram vinte e um (21) deputados federais evangélicos, hoje já são cento e cinco (105) deputados e quinze (15) senadores, o que equivale a $20 \%$ do Congresso. Dos cento e cinco (105) políticos, vinte e oito (28) são adventistas, quinze (15) batistas, dezessete (17) são da Igreja Universal do Reino de

\footnotetext{
${ }^{39} \mathrm{http}: / /$ dspace.est.edu.br:8080/jspui/bitstream/BR-SIFE/900/1/reinke_ad_tm343.pdf, acesso em 16/02/2021.

40 Traduções dos nomes das instituições, livres feitas pelo autor.

${ }^{41}$ http://dspace.est.edu.br:8080/jspui/bitstream/BR-S1FE/900/1/reinke_ad_tm343.pdf, acesso em 16/02/2021. 
Deus, seis (6) presbiterianos, cinco (5) da Igreja do Evangelho Quadrangular, três (3) da Igreja Sara Nossa Terra, três (3) da Igreja Internacional da Graça de Deus e os outros vinte e oito (28) membros de outras afiliações ${ }^{42}$. O que se observa é que o Congresso Nacional possui representantes de um sionismo cristão ativo. Observemos a fala de um Deputado Federal e pastor evangélico do partido político (PROS-Partido Republicano da Ordem Social) em 2016:

A relação da Bancada Evangélica com Israel tem se intensificado. Em novembro de 2016, a embaixada israelense promoveu o II Seminário BrasilIsrael no Instituto Rio Branco, em Brasília, com debates a respeito da diplomacia brasileira. No mesmo dia, a delegação israelense visitou a Câmara dos Deputados, onde foi recebida pelos membros da Liga Parlamentar de Amizade Brasil-Israel, presidida pelo deputado evangélico Jony Marcos, ocasião em que os evangélicos demonstraram seu apoio a Israel em conversa com os participantes da delegação israelense [...]". "[...] O governo do PT virou as costas para Israel. Eles priorizaram os árabes. A única vez que um presidente da República foi ao Oriente Médio e não pisou em Israel foi o presidente Lula. A presidente Dilma rejeitou um embaixador indicado por Israel só porque ele foi colono na Palestina, na Faixa de Gaza ${ }^{43}$.

É difícil prever ou imaginar quais os rumos que o panorama político brasileiro irá tomar nos próximos anos, pois a sociedade encontra-se inexoravelmente dividida, e assim como existe um abismo cada vez mais amplo entre os que apoiam e os que rejeitam o governo atual, existem aqueles que por conta de sua adesão a nova realidade ideológica, se sentem impelidos a apoiar incondicionalmente Israel, e para comprovar essa lealdade fazem o uso dos símbolos judaicos em suas manifestações, há também aqueles que em um movimento dialético tendem a construir sua antítese em discursos contra Israel, correndo-se o risco de adquirir posturas virulentas em relação ao judaísmo e aos judeus, que também podem ser confundidos com Israel.

Além da clara alusão a um alinhamento político-ideológico da nova direita recém-eleita no Brasil com os EUA, que historicamente produz uma política externa pró-Israel, verifica-se também que grande parte da base de apoio do novo governo está nas religiões neopentecostais, emissoras de um discurso sionista exacerbado pela religiosidade.

Uma outra motivação para o uso de símbolos nacionais israelenses e judaicos seria uma espécie de afronta a Igreja Católica, não pela via política, mas pela via religiosa, já que a Igreja

\footnotetext{
${ }^{42}$ https://congressoemfoco.uol.com.br/legislativo/veja-quais-deputados-e-senadores-fazem-parte-da-bancadaevangelica/, acesso em 16/02/2021.

${ }^{43}$ https://www.bbc.com/portuguese/noticias/2016/04/160420_entrevista_ronaldo_fonseca_paz_jerusalem_lgb, acesso em 25/12/2020.
} 
de Roma constantemente é acusada, por algumas denominações evangélicas estabelecidas no Brasil, de ter pervertido o verdadeiro cristianismo neotestamentário, que para a doutrina neopentecostal seria herdeiro direto do judaísmo.

Em resumo pode-se então inferir que a doutrina do dispensacionalismo, adotada por parte dos grupos evangélicos brasileiros, afirma que a volta do Messias se dará em Israel no momento em que os judeus aceitarem Jesus como o salvador e isso só ocorrerá se houver apoio incondicional das Igrejas Evangélicas ao Estado israelense.

Os elementos descritos acima podem fornecer algumas pistas sobre o fenômeno da aproximação da atual direita conservadora brasileira com o Estado de Israel, assim como levar a compreensão de um discurso sionista observado em denominações evangélicas no Brasil.

\section{Considerações finais}

O número de turistas em Israel em 2019 teve um aumento de 11\% em relação a 2018, com mais brasileiros viajando ao país, que recebeu 4.551 .600 milhões de visitantes. O Brasil é o $13^{\circ}$ na lista de principais emissores. Cerca de 82,1 mil brasileiros visitaram o país em 2019, sendo $31 \%$ a mais do que em 2018 e com crescimento de $50 \%$ nos dois últimos anos ${ }^{44}$. Segundo a Word Economic Forum em $2019^{45}$ Israel foi $57^{\circ}$ destino mais procurado por turistas, entretanto a pandemia de 2020/21 tem causado uma diminuição significativa em números de turistas em terras israelenses. O jornal Folha de São Paulo em dezembro de 2020 publicou uma matéria de página inteira sobre o Natal em Israel com dados alarmantes: Em 2020, Israel fechou o ano com só um pouco mais de 1milhão de visitantes, sendo que em 2019 recebeu 4,5 milhões de visitantes. A Palestina amarga números ainda piores, de 1,5 milhão em 2019 para praticamente 0 pessoas em 2020. A Basílica do Santo Sepulcro foi fechada em março de 2020 pela primeira vez desde 1349, quando a entrada de visitantes foi proibida motivada pela Peste Negra.

As diferenças entre turismo religioso e peregrinação não são claras e bem delimitadas, os lugares sagrados têm sido reificados pela lógica capitalista. Se analisarmos a peregrinação como uma busca salvacionista, da cura, da promessa etc., comumente essas jornadas são pontuadas pela dor e sacrifício, todavia em tempos da contemporaneidade, esses caminhos não podem ser

\footnotetext{
${ }^{44}$ https://www.panrotas.com.br/mercado/pesquisas-e-estatisticas/2019/09/brasil-e-o-32o-pais-mais-competitivono-turismo-veja-ranking_167371.html, acesso em 14/09/2021.

${ }^{45} \mathrm{http}: / /$ www3.weforum.org/docs/WEF_TTCR_2019.pdf, acesso em 14/09/2021. 
apenas pensados como algo construído simbolicamente, eles existem fisicamente e é a sua materialidade que os torna atraentes para os fiéis.

Quando usamos o termo turismo religioso as condições do sacrifício se dissolvem, pois os obstáculos pressupostos pela peregrinação são minimizados pela existência de uma série de facilidades proporcionadas por toda uma estrutura moderna como hotéis, restaurantes, lojas e toda espécie de lazer e conforto. Os conceitos de turismo religioso e peregrinação se apresentam muito mais complexos e se interpenetram constantemente, não sendo possível analisar essas duas categorias separadamente, como se uma excluísse de alguma forma a outra.

No Brasil o sionismo cristão está apoiado na doutrina escatológica do dispensacionalismo, que parte da ideia da volta iminente de Jesus e que esse retorno se dará em Israel e assim que os judeus o aceitarem como o Messias enviado por Deus. Essa doutrina é aceita pelas denominações protestantes, pentecostais e neopentecostais brasileiras pela influência norte-americana, apoiadas nos movimentos das políticas estadunidenses pró-Israel. A volta de Jesus para Israel leva os evangélicos das mais diversas denominações a assumirem um papel de garantia e salvaguarda da "Terra Santa", isso significa garantir a permanência do Estado israelense nas mãos dos judeus. O discurso sionista cristão proferido pelo atual governo é encampado de forma integral pelos membros das religiões neopentecostais.

As Igrejas evangélicas brasileiras têm se utilizado cada vez mais de uma simbologia judaica, são vários os motivos desse uso, desde a tentativa de se parecerem com os primeiros cristãos, até uma estratégia de afastamento da Igreja Católica, acusada por algumas dessas denominações de perverter o verdadeiro sentido do cristianismo original e a partir dessa ideia calcada em uma pressuposta legitimidade, se aproximam mais e mais do judaísmo, que segundo a concepção desses grupos é indissociável de Israel.

O ponto de inflexão entre peregrinação/turismo religioso e ascensão de uma política conservadora comandada pelo atual Presidente Jair Bolsonaro, encontra-se em um alinhamento político/ideológico com Israel, que é buscado pelos grupos de evangélicos, apoiadores da nova direita brasileira, e desta feita corroboram a doutrina do dispensacionalismo, da qual essas religiões são adeptas. Para alcançar seus objetivos é cada vez maior a promoção de viagens a Israel, mas não ao Estado moderno (embora seja inevitável) e sim, a um lugar do seu imaginário, construído a partir de elementos da narrativa bíblica (milenar), e que encontram ressonância com seu ideário religioso e político, onde não verifica-se a preocupação em estabelecer limites claros e bem definidos entre turismo religioso e peregrinação, ou seja, entre milênio e século, já que ambas as categorias contém em seu cerne, segundo a visão desses grupos, um objetivo maior que é confirmar a profecia messiânica. 


\section{Referências Bibliográficas}

ABUMANSUR, E.S. Religião e turismo: notas sobre as deambulações religiosas, in ABUMANSUR, E. S. (org.) Turismo religioso: ensaios antropológicos sobre a religião e o turismo. Campinas, SP: Papirus, 2003, p. 53-56.

BERGER, P. O Dossel Sagrado: Elementos para uma teoria sociológica da religião. $4^{\mathrm{a}}$ ed., São Paulo: Paulus, 2003. p.46

BERGER, Peter. The desecularization of the world: ressugent religion and world politics. Washington: W.B. E Publishing Company, 1999.

BENI, M. C. Análise estrutural do turismo. São Paulo: SENAC, 2000. p.21

BOURDIEU, Pierre. O Poder simbólico. Rio de Janeiro: Bertrand, 2012, p.10. Questões de sociologia. Rio de Janeiro: Marco Zero, 1980.

BURNS, P. Turismo e antropologia uma introdução. São Paulo: Chronos, 2002. p.54

CARLETTI, Anna e FERREIRA, Marcos A. Religião e as Relações Internacionais: dos debates teóricos ao papel do cristianismo e do islã. Curitiba: Juruá, 2016. p.58

COHEN, E. Pilgrimage and tourism: convergence and divergence. In: MORINIS, A. Journeys to Sacred Places. Westport: Greenwood Press, 1992, p.29-46

DIAS, R. O turismo religioso como segmento do mercado turístico, in DIAS, R. e SILVEIRA, E.J.S. da (orgs.). Turismo religioso: ensaios e reflexões. Campinas, SP: Alínea, 2003 (p. 7-37).

DUMAZEDIER, J. Lazer e cultura. São Paulo: Perspectiva, 1976. p.54 
DURKHEIM, E. Formas elementares da vida religiosa: o sistema totêmico na Austrália. São Paulo: Martins Fontes, 1996. p.59

ELIADE, Mircea. O sagrado e o profano. A essência das religiões. São Paulo: Martins Fontes, 2001. p.27

GOMES, Christianne.L.; ELIZALDE, Rodrigo. Horizontes latino-americanos do lazer / Horizontes latino-americanos del ocio. Belo Horizontes, UFMG, 2012. p.20

LUKÁCS, G. História e consciência de classe: estudos de dialética marxista. São Paulo: Martins Fontes, 1989. p. 50

MARCUSE, H. La agressividad em la sociedad industrial. Madrid: Alianza Editorial, 1971. p.50.

PEREIRA, M. Análise sobre a rede de negócios do turismo: uma abordagem conjuntural. Alemanha: Novas edições acadêmicas, 2017.p.25

TOPEL, Marta. Jerusalém \& São Paulo: a nova ortodoxia judaica em cena. Rio de Janeiro: Topbooks, 2005.

A inusitada incorporação do judaísmo em vertentes cristãs brasileiras: algumas reflexões. Revista Brasileira de História das Religiões. ANPUH, ANO IV, n.10, maio de 2011.

TURNER, V. TURNER, E. Image and pilgrimage in Christian culture. Nova York: Columbia University Press, 1978.

Dramas, campos e metáforas: ação simbólica na sociedade humana: Cornnel, 1976

O processo ritual, Brasília: UNB, 2005. 
VILAS BOAS, Nuno Fernando de Sá. A Pastoral do Turismo: da peregrinação ao santuário. Braga: 2012. P. 29

WEBER, Max. Três tipos puros de poder legítimo. In WEBER, Max. Três tipos de poder e outros escritos. Lisboa: Tribuna da História, 2005. p.22

http://ea.fflch.usp.br/conceito/liminaridade-e-communitas-victor-turner, acesso em $10 / 02 / 2021$.

https://houaiss.uol.com.br/corporativo/apps/uol_www/v5-4/html/index.php\#0

http://gsearch.vatican.va/search,

acesso

em

$18 / 05 / 201$

https://caminhandocommaria.com/roteiros/terra-santa-avivamento-09-dias-pe-fabio-de-melo, acesso em 02/02/202.

www.terrasantaviagens.com.br, acesso em 10/11/2020

https://www.gov.br/turismo/pt-br.

file://C:/Users/dtrav/Downloads/113341-Texto\%20do\%20artigo-223839-1-10-20160908.pdf , acesso em 02/02/2021.

https://www.ibge.gov.br/, acesso em 10/02/2021. https://g1.globo.com/politica/noticia/2020/01/13/50percent-dos-brasileiros-sao-catolicos31percent-evangelicos-e-10percent-nao-tem-religiao-diz-datafolha.ghtml, acesso em $10 / 02 / 2021$.

https://embratur.com.br/, acesso 1204/2019.

https://ri.ufs.br/bitstream/riufs/7153/2/CANDIDO_LUIZ_SANTOS_MAYNARD.pdf .acesso em $08 / 12 / 2020$.

https://link.springer.com/article/10.1007/s41603-019-00078-y, acesso em 16/02/2021. https://epoca.globo.com/mundo/israel-imaginario-usado-politicamente-pela-direita-pelaesquerda-23822015, acesso em 19/12/2020.

https://www.bbc.com/portuguese/brasil-47776408, acesso em 19/12/2019.

https://g1.globo.com/politica/eleicoes/2018/noticia/2018/10/18/datafolha-para-presidentevotos-validos-bolsonaro-59-haddad-41.ghtml, aceso em 19/12/2019. http://dspace.est.edu.br:8080/jspui/bitstream/BR-SIFE/900/1/reinke_ad_tm343.pdf, acesso em $16 / 02 / 2021$.

http://dspace.est.edu.br:8080/jspui/bitstream/BR-SIFE/900/1/reinke_ad_tm343.pdf, acesso em 16/02/2021. 
https://congressoemfoco.uol.com.br/legislativo/veja-quais-deputados-e-senadores-fazemparte-da-bancada-evangelica/, acesso em 16/02/2021.

https://www.bbc.com/portuguese/noticias/2016/04/160420_entrevista_ronaldo_fonseca_paz_j erusalem_lgb, acesso em 25/12/2020.

http://www3.weforum.org/docs/WEF_TTCR_2019.pdf, acesso em 14/09/2021.

https://www.panrotas.com.br/mercado/pesquisas-e-estatisticas/2019/09/brasil-e-o-32o-paismais-competitivo-no-turismo-veja-ranking_167371.html, acesso em 14/09/2021. 